\title{
COVID-19 in Renal Transplant Recipients: Case Series and a Brief Review of Current Evidence
}

\author{
Muhammed Ahmed Elhadedy a,b Yazin Marie ${ }^{a} \quad$ Ahmed Halawa $^{a, c}$ \\ aNephrology Department, Sheffield Teaching Hospital, Sheffield, UK; ${ }^{\mathrm{b}}$ Transplantation unit, Urology and \\ Nephrology Center, Mansoura University, Mansoura, Egypt; ${ }^{\mathrm{C} F a c u l t y}$ of Health and Life Sciences, University of \\ Liverpool, Liverpool, UK
}

\section{Keywords}

Coronavirus disease 2019 - Kidney transplantation . Immunosuppression

\begin{abstract}
By April 26, 2020, infections related to coronavirus disease 2019 (COVID-19) affected people from 210 countries and caused 203,818 reported deaths worldwide. A few studies discussed the outcome of COVID-19 in kidney transplant recipients. This short series demonstrates our experience in managing COVID-19 disease in renal transplant patients in the absence of strong evidence. We report 8 cases of kidney transplant recipients infected with COVID-19 (median age = 48.5 years; range $=21-71$ years), including 4 males and 4 females. The most frequently associated comorbidity was hypertension. The most common presenting features were fever and cough. The main radiological investigation was a portable chest X-ray. Other common features included lymphopenia, high C-reactive protein, and a very high ferritin level. Overall, 1 patient was managed as an outpatient, the remaining 7 required hospital admission, 1 of them referred to the intensive therapy unit. Management included supportive treatment (intravenous fluid therapy, monitoring re-
\end{abstract}

nal function, and symptomatic treatment with or without ward-based oxygen therapy depending on oxygen saturation) and discontinuation of the antiproliferative immunosuppressive drugs. Seven patients recovered and discharged home to self-isolate. One patient required intensive care treatment and mechanical ventilation. Supportive treatment could be sufficient for the management or to be tried first. We also found that short hospital stay with self-isolation on discharge reduces the burden on the health service and protect the staff and the public.

(c) 2020 S. Karger AG, Basel

\section{Introduction}

The new coronavirus disease 2019 (COVID-19) infection, emerged in Wuhan city, China, in December 2019, has close genomic structural similarities with the severe acute respiratory syndrome coronavirus (SARS-CoV) that caused the SARS pandemic in 2003 and the middle east respiratory syndrome coronavirus (MERS-CoV) that caused (MERS) epidemic in 2012 [1, 2]. By April 26, 2020, infections related to COVID-19 affected people from 210 countries and caused 203,818 reported deaths worldwide.

$\begin{aligned} & \text { karger@karger.com } \\ & \text { www.karger.com/nef }\end{aligned}$
Karger ${ }^{\prime /}$

Ahmed Halawa

Northern General Hospital, University of Liverpool Herries Road

Sheffield S5 7AU (UK)

ahmed.halawa@liverpool.ac.uk 
In the UK, mortality cases exceeded 30,000 so far. There is a common belief among transplant clinicians that kidney transplant recipients have a high risk of infection due to long-term immunosuppression and associated comorbidities. Data, clinical picture, and outcomes of COVID-19 in kidney transplant recipients are scarce [3]. Therefore, we report 8 cases of kidney transplant recipients infected with COVID-19.

\section{Case Reports}

Patient 1: a 21-year-old female - who had a deceased donor kidney transplant in December 2019 presented on March 30 with fever $\left(39.2^{\circ} \mathrm{C}\right)$. She felt lethargic and generally unwell, with no respiratory symptoms. Clinical examination was unremarkable (apart from high temperature), and the chest X-ray was clear. Urine and blood cultures were negative. A nasal and throat swab for COVID-19 tested positive. She is hypertensive and maintained on calcium channel and $\beta$-blockers. She was on prednisone $5 \mathrm{mg}$ once daily (OD), tacrolimus $2 \mathrm{mg}$ twice a day (BD), and mycophenolate mofetil $250 \mathrm{mg}(\mathrm{BD})$. She was admitted and received supportive medical in the form of IV fluids and paracetamol. We discontinued MMF and discharged after 2 days with full recovery and stable kidney functions.

Patient 2: a 71-year-old male with hypertensive nephropathy who received a kidney graft in February 2016. He had a history of colon adenocarcinoma in June 2019. His baseline Cr was 240-260 $\mu \mathrm{mol} / \mathrm{L}$. His immunosuppressive regimen included prednisolone $5 \mathrm{mg}$ OD, tacrolimus (trough level was $6.4 \mathrm{ng} / \mathrm{mL}$ ), and MMF 250 $\mathrm{mg}$ BD. He was also on calcium channel blockers and proton pump inhibitors. He presented on April 2 with a dry cough with no other symptoms but stable vital signs. However, a chest X-ray revealed a patchy bilateral consolidation. He was tested positive for COVID-19 nasal and throat swab, therefore admitted to hospital. MMF discontinued and received supportive treatment IV fluid and symptomatic treatment. He was discharged 2 days later with stable kidney functions.

Patient 3: a 50-year-old male with a history of Wegner's granulomatosis received a live donor kidney transplant in February 2020. He presented on April 3 with productive cough and was tested positive for SARS-CoV-2 RNA despite unremarkable clinical examination. The chest $\mathrm{X}$-ray was clear, and kidney function tests were stable. His immunosuppressive drugs were prednisolone 5 mg OD, tacrolimus (trough level was $13.4 \mathrm{ng} / \mathrm{mL}$ ), and MMF 500 $\mathrm{mg} \mathrm{BD}$. The management included discontinuation of MMF, reduction of tacrolimus dose, and self-isolation at home. He was advised to drink plenty of fluids and report to the unit any new symptoms.

Patient 4: a 63-year-old male with a history of IgA nephropathy with a deceased donor kidney transplant in December 2005. He is hypertensive and maintained on calcium channel blockers. $\mathrm{He}$ presented on March 20 with fever $\left(38.8^{\circ} \mathrm{C}\right)$ and acute kidney injury (AKI; Cr $297 \mu \mathrm{mol} / \mathrm{L}$, baseline $110 \mu \mathrm{mol} / \mathrm{L}$ ). The chest X-ray showed patchy bilateral consolidation, and SARS-CoV-2 RNA was positive. Blood culture was positive for staphylococcus aureus. Serum C-reactive protein (CRP) was $175 \mathrm{mg} / \mathrm{L}$, and serum ferritin was $929 \mu \mathrm{g} / \mathrm{L}$. His immunosuppressive regimen was prednisolone
$5 \mathrm{mg}$ OD, tacrolimus (trough level was $2.7 \mathrm{ng} / \mathrm{mL}$ ), and MMF 500 $\mathrm{mg} \mathrm{BD}$. The patient was admitted and received IV broad-spectrum antibiotics and paracetamol. We stopped MMF and increased the tacrolimus dose. Kidney function tests improved (serum $\mathrm{Cr}$ decreased to $113 \mu \mathrm{mol} / \mathrm{L}$ ). The patient recovered and discharged home after 7 days.

Patient 5: A 47-year-old female with bronchial asthma received a deceased donor kidney transplant in December 2019. She was maintained on prednisolone $5 \mathrm{mg} \mathrm{OD}$, tacrolimus with levels between 5 and $7 \mathrm{ng} / \mathrm{mL}$, and MMF $250 \mathrm{mg}$ BD. She presented on April 6 with dry cough and shortness of breath but no fever. Chest $\mathrm{X}$-ray revealed bilateral middle and lower zone consolidation. Nose and throat viral swabs for COVID-19 were positive. Kidney function tests showed AKI (Cr $302 \mu \mathrm{mol} / \mathrm{L}$ and baseline 162 $\mu \mathrm{mol} / \mathrm{L}$ ), and mild proteinuria (urine protein/Cr ratio $127 \mathrm{mg}$ / $\mathrm{mmol}$ and baseline $<30 \mathrm{mg} / \mathrm{mmol}$ ). Microbiology workup showed positive urine culture for E. coli and negative blood culture. Serum CRP on admission was $344 \mathrm{mg} / \mathrm{L}$ and ferritin $2684 \mu \mathrm{g} / \mathrm{L}$, with leukocytosis (white cell counts $25.8 \times 10^{9} / \mathrm{L}$ ) and lymphopenia (lymphocyte count $0.7 \times 10^{9} / \mathrm{L}$ ). Serum interleukin-6 was $22.2 \mathrm{pg} / \mathrm{mL}$ $(n=0-7 \mathrm{pg} / \mathrm{mL})$. She was tachypnoeic with a respiratory rate of 36 breaths $/ \mathrm{min}$, and the peripheral oxygen saturation was $80 \%$, therefore admitted to the intensive therapy unit (ITU) for non-invasive ventilation (continuous positive airway pressure for type 1 respiratory failure). Her respiratory functions got worse, and she required intubation and invasive ventilation. Bronchoalveolar lavage showed moderate growth of aspergillus. She received broad-spectrum antibiotics and antifungals. No specific antiviral drugs were given. MMF was discontinued. Her kidney functions deteriorated, and she became anuric; therefore, continuous veno-venous haemodiafiltration $(\mathrm{CVVH})$ was commenced. After 14 days, she was weaned off mechanical ventilation and transferred from the ITU to the medical ward. Her kidney functions improved (estimated glomerular filtration rate was $17 \mathrm{~mL} / \mathrm{min}$ per $1.73 \mathrm{~m}^{2}$, urine protein/Cr ratio, $40 \mathrm{mg} / \mathrm{mmol}$ ), and $\mathrm{CVVH}$, stopped. She was discharged 7 days later.

Patient 6: A 71-year-old female with type II diabetes, received deceased donor kidney transplantation in November 2015. Her immunosuppressive therapy included prednisolone, tacrolimus, and MMF. She presented on April 2 with fever $\left(38.5^{\circ} \mathrm{C}\right)$ and no other complaint. Chest X-ray showed bilateral peripheral mid and lower zone consolidation. Nasal and throat swabs were positive for COVID-19 RNA. Kidney function tests showed no change from baseline, and microbiological tests were negative. Serum CRP was $19 \mathrm{mg} / \mathrm{L}$, while serum ferritin was $1,835 \mu \mathrm{g} / \mathrm{L}$. She was admitted to the medical ward for adequate hydration and symptomatic treatment. MMF was discontinued and discharged after 4 days with full recovery.

Patient 7: A 40-year-old female with hypertension received deceased donor kidney transplantation in June 2017. She is maintained on prednisolone, tacrolimus, and MMF. Other medications included amlodipine and proton pump inhibitors. On April 10, she presented with fever $\left(39^{\circ} \mathrm{C}\right)$ and dry cough with no other symptoms. Nose and throat swabs for COVID-19 RNA were positive. Kidney function tests were stable and microbiological analyses were negative. She was admitted to the medical ward, where MMF was discontinued, Paracetamol and IV fluids were administered and discharged after 4 days with full recover.

Patient 8: A 38-year-old male with a failing kidney transplant from June 2013 presented with productive cough (of clear sputum) 
Table 1. Patients' demographics and clinical characteristics of 8 kidney transplant recipients with COVID-19 infection

\begin{tabular}{|c|c|c|c|c|c|c|c|}
\hline Patient & Age/sex & Tx date & Comorbidities & Fever & Respiratory involvements & $\begin{array}{l}\text { Renal } \\
\text { involvements }\end{array}$ & $\begin{array}{l}\text { Baseline } \\
\text { immunosuppression }\end{array}$ \\
\hline 1 & $21 / \mathrm{F}$ & Dec 2019 & Hypertension & Yes & No & No & Pred-Tac-MMF \\
\hline 3 & $50 / \mathrm{M}$ & Feb 2020 & No & No & Productive cough & No & Pred-Tac-MMF \\
\hline 4 & $63 / \mathrm{M}$ & Dec 2005 & Hypertension & Yes & No & AKI & Pred-Tac-MMF \\
\hline 5 & $47 / \mathrm{F}$ & Dec 2019 & Bronchial asthma, aspergillosis & No & Dry cough $+\mathrm{SOB}$ & AKI & Pred-Tac-MMF \\
\hline 8 & $38 / \mathrm{M}$ & Jun 2013 & No & Yes & Productive cough + SOB & No & Pred-Tac-Aza \\
\hline
\end{tabular}

COVID-19, coronavirus disease 2019; F, female; M, male; Tx date, date of transplant; post-Tx, post-transplant; DM, diabetes mellitus; SOB, shortness of breath; Pred, prednisolone; Tac, tacrolimus; MMF, mycophenolic acid; Aza, azathioprine.

Table 2. Kidney function tests

\begin{tabular}{llllll}
\hline Patient & $\begin{array}{l}\text { Baseline Cr } \\
(\mathrm{eGFR} \mathrm{mL/min} \\
\left.\text { per } 1.73 \mathrm{~m}^{2}\right)\end{array}$ & $\begin{array}{l}\text { On admission Cr } \\
(\mathrm{eGFR} \mathrm{mL/min} \\
\left.\text { per } 1.73 \mathrm{~m}^{2}\right)\end{array}$ & $\begin{array}{l}\text { On discharge Cr } \\
(\mathrm{eGFR} \mathrm{mL/min} \\
\left.\text { per } 1.73 \mathrm{~m}^{2}\right)\end{array}$ & $\begin{array}{l}\text { Baseline urine } \\
\text { protein/Cr ratio } \\
(\mathrm{mg} / \mathrm{mmol})\end{array}$ & $\begin{array}{l}\text { On admission urine } \\
\text { protein/Cr ratio } \\
(\mathrm{mg} / \mathrm{mmol})\end{array}$ \\
\hline 1 & $85(84.4)$ & $86(83.2)$ & $84(85.6)$ & 37 & 34 \\
2 & $256(20.8)$ & $242(22.3)$ & $250(21.5)$ & 16 & 53 \\
3 & $184(36)$ & $182(36.5)$ & $185(35.8)$ & 14 & 12 \\
4 & $110(61.2)$ & $297(18.4)$ & $113(59.3)$ & $<5$ & 50 \\
5 & $162(32.2)$ & $302(15.2)$ & $304(15.1)$ & 40 & 49 \\
6 & $252(16)$ & $260(15.4)$ & $258(15.5)$ & 42 & 56 \\
7 & $268(18.4)$ & $270(18.3)$ & $266(18.6)$ & 56 & 70 \\
8 & $648(8.6)$ & $650(8.5)$ & $647(8.6)$ & 65 & \\
\hline
\end{tabular}

eGFR, estimated glomerular filtration rate.

Table 3. Blood test results on the day of admission

\begin{tabular}{llllll}
\hline Patient & $\begin{array}{l}\text { White cell count, } \\
\times 10^{9} / \mathrm{L}(3.5-10)\end{array}$ & $\begin{array}{l}\text { Lymphocyte count, } \\
\times 10^{9} / \mathrm{L}(1-3.5)\end{array}$ & $\begin{array}{l}\text { Serum CRP, } \\
\mathrm{mg} / \mathrm{L}(<5)\end{array}$ & $\begin{array}{l}\text { Serum ferritin, } \\
\mu \mathrm{g} / \mathrm{L}(25-200)\end{array}$ & $\begin{array}{l}\text { Serum IL-6 } \\
(0-7)\end{array}$ \\
\hline 1 & 3.8 & 0.89 & 139 & - & - \\
2 & 8.0 & 0.28 & 105 & - & - \\
3 & 5.1 & 0.38 & 45 & - & - \\
4 & 11.6 & 0.57 & 175 & 929 & - \\
5 & 28.5 & 0.71 & 344 & 19 & - \\
6 & 4.7 & 0.75 & 80 & - & - \\
7 & 9.1 & 0.88 & 112 & - & - \\
8 & 9.6 & 0.32 & & & - \\
\hline
\end{tabular}

CRP, C-reactive protein; IL-6, interleukin-6.

and shortness of breath for 2 days. He was maintained on prednisolone $5 \mathrm{mg} \mathrm{OD}$, tacrolimus, and azathioprine. On admission on March 20, he had tachypnoea and hypoxaemia with oxygen saturation of $89 \%$ on room air, which improved to $>96 \%$ on $4 \mathrm{~L} / \mathrm{min}$ oxygen through a nasal cannula. Nasal and throat swabs were positive for COVID-19 RNA. Kidney function tests remained unchanged $(\mathrm{Cr} 648 \mu \mathrm{mol} / \mathrm{L})$ despite the high baseline Cr. Chest X-ray revealed bilateral infiltrates. Management included discontinuation of azathioprine, reduction of tacrolimus dose, and increase of prednisolone dose to $15 \mathrm{mg} \mathrm{OD}$. He did not require any dialysis. Oxygen saturation recovered to $>95 \%$ on room air, and the patient was discharged after 2 days. The patients' demographics, clinical characteristics, blood test results, management, and the outcome are summarized in Tables 1-4. 
Table 4. Management and outcome of the 8 patients

\begin{tabular}{|c|c|c|c|c|}
\hline Patient & Chest X-ray & Management & $\begin{array}{l}\text { Length of } \\
\text { hospital stay }\end{array}$ & Outcome \\
\hline 1 & Clear & Discontinue MMF + supportive treatment & 2 days & Discharged, asymptomatic \\
\hline 3 & Clear & Discontinue MMF + self-isolation at home & $2 \mathrm{~h}$ & Stayed at home, full recovery \\
\hline 4 & Bilateral patchy consolidation & Discontinue MMF + supportive treatment & 7 days & Discharged, asymptomatic \\
\hline 5 & Bilateral patchy consolidation & Discontinue $\mathrm{MMF}+$ mechanical ventilation $+\mathrm{CVVH}$ & 21 days & Discharged, asymptomatic \\
\hline 8 & Bilateral patchy consolidation & Discontinue Aza + oxygen therapy & 2 days & Discharged, still has a cough \\
\hline
\end{tabular}

na, not applicable; MMF, mycophenolate mofetil; Aza, azathioprine; ITU, intensive therapy unit; CVVH, continuous veno-venous hemofiltration.

Fig. 1. Shows AKI (blue arrow in case 4 and red arrow in case 5), with the arrow pointing to the date of diagnosis. AKI, acute kidney injury.

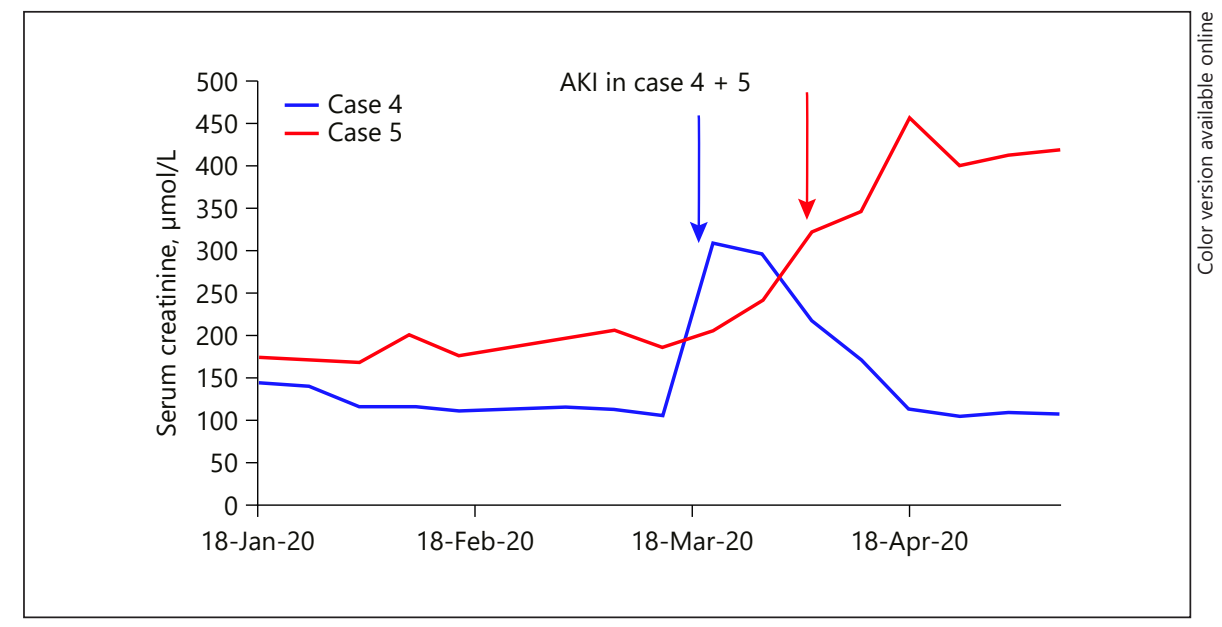

\section{Discussion}

In this report, we present our experience with 8 cases of COVID-19 infection in kidney transplant patients from Sheffield Kidney Institute, UK. The median age of patients was 48.5 years (ranging from 21 to 71 years), including 4 males and 4 females. Three patients had kidney transplantation within the last 3 months, and the rest were transplanted for more than a year. The most common initial symptoms were fever (5 patients) and cough (5 patients). All 8 patients were receiving prednisone and tacrolimus, 7 patients were receiving mycophenolate mofetil, and 1 patient was receiving azathioprine. Two patients had AKI (Fig. 1) (cases 4 \& 5); 1 of them required continuous veno-venous hemofiltration (case 5). Blood results showed that all patients had lymphopenia and high CRP. Three patients had elevated serum ferritin, and 1 patient had high serum interleukin-6 (IL-6). A portable chest X-ray was performed in 7 patients, which was clear in 2 of them, and the rest had a picture consistent with viral pneumonia.

One of our 8 patients was managed as an outpatient and advised to self-isolate at home, with the remaining 7 requiring hospital admission. One patient required ITU admission, where she needed mechanical ventilation (case 5). Bronchoalveolar lavage of this patient confirmed aspergillosis for which she is receiving antifungal treatment (another contributing factor for deterioration). Another patient required ward-based oxygen therapy (case 8). The other 6 patients received supportive therapy on the renal ward (intravenous fluid therapy, monitoring renal function, and symptomatic treatment with or without ward-based oxygen therapy based on the oxygen saturation). Antiproliferative immunosuppressive drugs were discontinued for all patients.

Transplant patients are at a high risk of infection due to multiple risk factors, including immunosuppression, underlying $\mathrm{CKD}$, and associated comorbidities, especial- 
ly hypertension and diabetes [4]. Six patients had multiple comorbidities ( 4 had hypertension, 1 had type II DM, 1 had bronchial asthma and aspergillosis, and 1 had a history of cancer). Many studies discussed the outcome of such comorbidities in COVID-19 patients [5-10]. These studies reported that hypertensive and diabetic patients have a double-fold risk of infection, while COPD patients have a 5-fold risk.

One of our patients (case 2) had a post-transplant malignancy (adenocarcinoma of the sigmoid colon). Liang et al. [11] reported that $1 \%$ of COVID-19 patients had a history of malignancy, which was higher than the prevalence of cancer in the overall Chinese population (0.29\%). They reported that the most frequent tumour was lung cancer [11]. Other studies supported this observation by declaring that the incidence of malignancy was $0.9 \%$ among their reported COVID-19 patients [5].

In our case series, the most frequent presentation was fever (5 patients) and cough (5 patients). Fever was reported to be the most common symptom followed by cough $[9,12-19]$. Two large studies demonstrated that $82-87 \%$ of their patients had a fever, while patients with cough ranged from 44 to $65.7 \%[12,14]$.

Two of our patients (shown in Fig. 1) had AKI (cases $4 \& 5$ ); 1 of them required renal replacement therapy in the form of CVVH (case 5). Early studies reported that the incidence of AKI was low (3-9\%) in those with COVID-19 infection $[5,8,20,21]$. However, recent studies showed a higher frequency of renal abnormalities. Cheng et al. [21] reported that among 710 patients, $44 \%$ had proteinuria, $26.7 \%$ had haematuria, and $14.1 \%$ had high serum $\mathrm{Cr}$. The pathophysiology of renal involvement is still unclear, but theories suggest a cytokine storm syndrome or direct renal injury by the virus. Scientists succeeded in isolating SARS-CoV-2 from a urine sample of an infected patient, suggesting the kidney can be a target of this virus [22]. In cases of AKI associated with SARS and MERS, continuous renal replacement therapy showed promising results $[23,24]$. It was assumed that high-volume hemofiltration could remove inflammatory cytokines (tumour necrosis factor, IL- 6 , and IL- $1 \beta$ ) involved in the pathogenesis of renal injury [25]. Therefore, continuous renal replacement therapy may play a role in the management of AKI in COVID-19 patients.

All our patients had lymphopenia and a high CRP level. Guan et al. [5] reported that $83.2 \%$ of infected patients had lymphopenia on admission. Another study suggested a link between lymphopenia and acute respiratory distress syndrome (ARDS) development [26]. Two more reports demonstrated that patients who had a significantly low lymphocyte/white blood cell ratio both on admission and during hospitalization had fatal outcomes [27, 28]. Many studies showed that COVID-19 infection is associated with high CRP. Guan et al. [5] reported that $60.7 \%$ of patients had an elevated CRP, while severe cases had a higher level compared to the non-severe ones (81.5 vs. $56.4 \%$ for CRP). Other reports noticed that high CRP could be linked to unfavourable outcomes, such as ARDS development [26], myocardial damage [29], and death [27]. Serum ferritin was measured in only 3 of our patients, and the level was very high. Many reports suggested that higher serum ferritin is associated with ARDS development [26] and death [4]. Ferritin is an acute-phase protein, but we are not sure about the sensitivity and specificity concerning the outcome.

IL-6 is considered a novel biomarker for COVID-19 diagnosis. One patient (case 5) had a high level. Chen et al. [20] reported that 52\% (51/99) of patients had high IL-6 levels on admission. Other studies suggested that increased IL- 6 levels can be associated with an increased risk of mortality [26]. Since we are not sure about the sensitivity and the specificity of IL-6, we did not measure it routinely. Also, there is no clear evidence to support the role of IL-6 blocker (tocilizumab) in treatment of COVID-19 in both transplant and non-transplant population.

A chest X-ray was performed in 7 patients. Five of them had bilateral patchy consolidation, and 2 patients had no classical changes of COVID-19. The reported radiological data of COVID-19 infection focused on computerized chest tomography (CT) findings [30-32]. This practice put a significant burden on radiology departments and set up a challenge for infection control in the radiology suite. The American College of Radiology states that CT decontamination may disrupt their service availability and suggests that portable chest X-ray should be considered to reduce the transmission of infection [33]. The Italian and British hospitals employ chest X-ray as a first-line triage tool as the results of COVID-19 testing may take more time $[34,35]$. The British Society of Thoracic Imaging (BSTI) issued guidelines which state that there is no recommended use of CT unless there is high suspicion with normal or uncertain appearance of CXR in a seriously ill patient [36]. It is also essential for clinicians of all specialities to be familiar with the radiological findings of COVID-19 on chest X-ray.

Regarding the management, 6 of our patients had their antiproliferative drugs stopped, and they received supportive treatment; 1 patient needed oxygen therapy, and 1 required mechanical ventilation. On the other hand, none of our patients received specific antiviral drugs. When 
managing immunosuppression in kidney transplant recipients, the age, the severity of infection, the post-transplant duration, any other associated comorbidity, tissue mismatch, and any episodes of rejection should be considered. Generally speaking, in mild infections, the usual practice is to continue or reduce the dose of immunosuppressive drugs. While we declare that the small sample size of this study cannot give firm recommendations, we suggest discontinuation of the antiproliferative drugs (azathioprine and mycophenolate mofetil) while monitoring the patients closely. In our unit, we prefer to stop the antiproliferative drugs first in cases of severe infection, particularly in the absence of clear UK guidelines or recommendations and unpredictable course of COVID-19 infection in this cohort of patients. In severe cases requiring mechanical ventilation, we can argue about ceasing calcineurin inhibitors while maintaining corticosteroid therapy. Undoubtedly, the treatment should be individualized based on the careful assessment of each patient.

During the SARS pandemic, convalescent plasma derived from the blood of recovered patients - was used as a treatment option. However, its efficacy was questionable as a meta-analysis revealed that many studies had small sample sizes and some lacked control groups [37]. Currently, the US Food and Drug Administration investigates the efficacy of convalescent plasma as a treatment option for patients with severe COVID-19 infection [38].

$\mathrm{Chu}$ and colleagues [39] studied the combination of lopinavir and ritonavir among SARS-CoV patients, but the results were discouraging. Other reports suggested that remdesivir (a broad-spectrum antiviral nucleotide prodrug) can be effective against MERS-CoV and SARS$\mathrm{CoV}$ infections $[40,41]$. Remdesivir was used as a compassionate treatment that showed promising results [42]. Besides, the Adaptive COVID-19 Treatment Trial (NCT04280705) proved that remdesivir-treated patients had $31 \%$ faster time to recovery when compared to control [43]. Based on the previous results, the US Food and Drug Administration has authorized the use of remdesivir as a treatment option for hospitalized COVID-19 patients [43].

\section{Conclusion}

In the above report, the presentations of COVID-19 infected renal transplant patients were not different from the general population where fever and cough were the most frequent symptoms. We believe that our transplant patients did not behave differently from the general pop- ulation as far as COVID-19 infection is concerned. Because of the small sample size, we could not evaluate the effect of immunosuppression on the course of the disease, but at least it is not a detrimental effect. Based on our experience, supportive treatment could be sufficient or at least to be tried first. It is worth mentioning that the clinical examination supported by simple bedside measures such as oxygen saturation and portable CXR rather than CT scan could be enough and limit the spread of infection. We also found that short hospital stay with self-isolation on discharge reduces the burden on the health service and protect the staff and the public. Since remdisivir was approved for the treatment of COVID-19 and its interaction with $\mathrm{CNI}$ is yet unknown, we recommend treatment with remdisivir in a hospital setting where CNI drug level monitoring is available.

\section{Statement of Ethics}

Ethics approval was not required as the authors presented a retrospective observational case series study concerned with the novel COVID-19 infection in the kidney transplant population.

\section{Conflict of Interest Statement}

The authors have no conflicts of interest to declare.

\section{Funding Sources}

The authors declare that no funding was obtained.

\section{Author Contributions}

Muhammed Ahmed Elhadedy and Ahmed Halawa have participated in the research design, writing of the paper, and analysis of the data. Yazin Marie has participated in the writing of the paper.

\section{References}

1 Lu R, Zhao X, Li J, Niu P, Yang B, Wu H, et al. Genomic characterisation and epidemiology of 2019 novel coronavirus: implications for virus origins and receptor binding. Lancet. 2020 Feb 22;395(10224):565-74.

2 Wu F, Zhao S, Yu B, Chen YM, Wang W, Song ZG, et al. A new coronavirus associated with human respiratory disease in China. $\mathrm{Na}$ ture. 2020 Mar;579(7798):265-9.

3 Zhu L, Xu X, Ma K, Yang J, Guan H, Chen S, et al. Successful recovery of COVID-19 pneumonia in a renal transplant recipient with long-term immunosuppression. Am J Transplant. 2020 Jul;20(7):1859-63. 
4 Zhou F, Yu T, Du R, Fan G, Liu Y, Liu Z, et al. Clinical course and risk factors for mortality of adult inpatients with COVID-19 in Wuhan, China: a retrospective cohort study. Lancet. 2020 Mar 28;395(10229):1054-62.

5 Guan WJ, Ni ZY, Hu Y, Liang WH, Ou CQ, $\mathrm{He}$ JX, et al. Clinical characteristics of coronavirus disease 2019 in China. N Engl J Med. 2020 April 30;382(18):1708-20.

6 Huang C, Wang Y, Li X, Ren L, Zhao J, Hu Y, et al. Clinical features of patients infected with 2019 novel coronavirus in Wuhan, China. Lancet. 2020 Feb 15;395(10223):497-506.

7 Liu W, Tao ZW, Wang L, Yuan ML, Liu K, Zhou L, et al. Analysis of factors associated with disease outcomes in hospitalized patients with 2019 novel coronavirus disease. Chin Med J. 2020 May 5;133(9):1032-8.

8 Wang D, Hu B, Hu C, Zhu F, Liu X, Zhang J, et al. Clinical characteristics of 138 hospitalized patients with 2019 novel coronavirus-infected pneumonia in Wuhan, China. JAMA. 2020 Mar 17;323(11):1061-69.

$9 \mathrm{Xu}$ XW, Wu XX, Jiang XG, Xu KJ, Ying LJ, Ma $\mathrm{CL}$, et al. Clinical findings in a group of patients infected with the 2019 novel coronavirus (SARS-Cov-2) outside of Wuhan, China: retrospective case series. BMJ. 2020 Feb 19; 368:m606.

10 Zhang JJ, Dong X, Cao YY, Yuan YD, Yang YB Yan YQ, et al. Clinical characteristics of $140 \mathrm{pa}-$ tients infected with SARS-CoV-2 in Wuhan, China. Allergy. 2020 Jul;75(7):1730-41.

11 Liang W, Guan W, Chen R, Wang W, Li J, Xu $\mathrm{K}$, et al. Cancer patients in SARS-CoV-2 infection: a nationwide analysis in China. Lancet Oncol. 2020 Mar;21(3):335-7.

12 Chen J, Qi T, Liu L, Ling Y, Qian Z, Li T, et al Clinical progression of patients with $\mathrm{COV}$ ID-19 in Shanghai, China. Journal of Infection. 2020 May;80(5):e1-6.

13 Lo IL, Lio CF, Cheong HH, Lei CI, Cheong $\mathrm{TH}$, Zhong X, et al. Evaluation of SARSCoV-2 RNA shedding in clinical specimens and clinical characteristics of 10 patients with COVID-19 in Macau. Int J Biol Sci. 2020; 16(10): 1698-707.

14 Tian S, Hu N, Lou J, Chen K, Kang X, Xiang $Z$, et al. Characteristics of COVID-19 infection in Beijing. J Infect. 2020 Apr;80(4):4016.

15 Wu J, Liu J, Zhao X, Liu C, Wang W, Wang $\mathrm{D}$, et al. Clinical characteristics of imported cases of COVID-19 in Jiangsu Province: a multicenter descriptive study. Clin Infect Dis. 2020 Jul 28;71(15):706-12.

$16 \mathrm{Xu} \mathrm{YH,} \mathrm{Dong} \mathrm{JH,} \mathrm{An} \mathrm{WM,} \mathrm{Lv} \mathrm{XY,} \mathrm{Yin} \mathrm{XP,}$ Zhang JZ, et al. Clinical and computed tomographic imaging features of novel coronavirus pneumonia caused by SARS-CoV-2. J Infect. 2020 Apr;80(4):394-400.

17 Yang W, Cao Q, Qin L, Wang X, Cheng Z, Pan A, et al. Clinical characteristics and imaging manifestations of the 2019 novel coronavirus disease (COVID-19):A multi-center study in Wenzhou city, Zhejiang, China. J Infect. 2020 Apr;80(4):388-93.
18 Young BE, Ong SWX, Kalimuddin S, Low JG, Tan SY, Loh J, et al. Epidemiologic features and clinical course of patients infected with SARS-CoV-2 in Singapore. JAMA. 2020 Apr 21;323(15):1488-94.

19 Zhao W, Zhong Z, Xie X, Yu Q, Liu J. Relation between chest $\mathrm{CT}$ findings and clinical conditions of coronavirus disease (COVID-19) pneumonia: a multicenter study. AJR Am J Roentgenol. 2020 May;214(5):1072-7.

20 Chen N, Zhou M, Dong X, Qu J, Gong F, Han $\mathrm{Y}$, et al. Epidemiological and clinical characteristics of 99 cases of 2019 novel coronavirus pneumonia in Wuhan, China: a descriptive study. Lancet. 2020 Feb 15;395(10223):507-13.

21 Cheng Y, Luo R, Wang K, Zhang M, Wang Z, Dong L, et al. Kidney disease is associated with in-hospital death of patients with COVID-19. Kidney Int. 2020 May;97(5):829-38.

22 Sun J, Zhu A, Li H, Zheng K, Zhuang Z, Chen $\mathrm{Z}$, et al. Isolation of infectious SARS-CoV-2 from urine of a COVID-19 patient. Emerg Microbes Infect. 2020 Dec;9(1):991-3.

23 Chu KH, Tsang WK, Tang CS, Lam MF, Lai FM, To KF, et al. Acute renal impairment in coronavirus-associated severe acute respiratory syndrome. Kidney Int. 2005 Feb;67(2): 698-705.

24 Arabi YM, Arifi AA, Balkhy HH, Najm H, Aldawood AS, Ghabashi A, et al. Clinical course and outcomes of critically ill patients with Middle East respiratory syndrome coronavirus infection. Ann Intern Med. 2014 Mar 18; 160(6):389-97.

25 Ghani RA, Zainudin S, Ctkong N, Rahman AF, Wafa SR, Mohamad M, et al. Serum IL-6 and IL-1-ra with sequential organ failure assessment scores in septic patients receiving high-volume haemofiltration and continuous venovenous haemofiltration. Nephrology. 2006 Oct;11(5):386-93.

26 Wu C, Chen X, Cai Y, Xia J, Zhou X, Xu S, et al. Risk factors associated with acute respiratory distress syndrome and death in patients with coronavirus disease 2019 pneumonia in Wuhan, China. JAMA Intern Med. 2020 Jul 1; 180(7):934-43.

27 Deng Y, Liu W, Liu K, Fang YY, Shang J, Zhou $\mathrm{L}$, et al. Clinical characteristics of fatal and recovered cases of coronavirus disease 2019 (COVID-19) in Wuhan, China: a retrospective study. Chin Med J. 2020 Jun 5;133(11): 1261-7.

28 Qin C, Zhou L, Hu Z, Zhang S, Yang S, Tao Y, et al. Dysregulation of immune response in patients with COVID-19 in Wuhan, China. Clin Infect Dis. 2020 Jul 28;71(15):762-8.

29 Shi S, Qin M, Shen B, Cai Y, Liu T, Yang F, et al. Association of cardiac injury with mortality in hospitalized patients with COVID-19 in Wuhan, China. JAMA Cardiol. 2020 Jul 1; 5(7):802-10.

30 Ai T, Yang Z, Hou H, Zhan C, Chen C, Lv W, et al. Correlation of chest CT and RT-PCR testing in coronavirus disease 2019 (COVID-19) in China: a report of 1014 cases. Radiology. 2020 Aug;296(2):E32-40.
31 Bernheim A, Mei X, Huang M, Yang Y, Fayad $\mathrm{ZA}$, Zhang $\mathrm{N}$, et al. Chest CT findings in coronavirus disease-19 (COVID-19): relationship to duration of infection. Radiology. 2020 Jun; 295(3):200463.

32 Zhou S, Wang Y, Zhu T, Xia L. CT features of coronavirus disease 2019 (COVID-19) pneumonia in 62 patients in Wuhan, China. AJR Am J Roentgenol. 2020 Jun;214(6):1287-94.

33 ACR. ACR Recommendations for the use of Chest Radiography and Computed Tomography (CT) for Suspected COVID-19 Infection [Internet]. USA: American College of Radiology; 2020

34 Wong HYF, Lam HYS, Fong AH, Leung ST, Chin TW, Lo CSY, et al. Frequency and distribution of chest radiographic findings in COVID-19 positive patients. Radiology. 2019 Aug;296(2):E72-8.

35 Hare SS, Rodrigues JCL, Nair A, Jacob J, Upile $\mathrm{S}$, Johnstone A, et al. The continuing evolution of COVID-19 imaging pathways in the UK: a British Society of Thoracic Imaging expert reference group update. Clin Radiol. 2020;75(6):399-404.

36 BSTI. COVID-19 BSTI statement and guidance [Internet]. UK: British Society of Thoracic Imaging; 2020

37 Mair-Jenkins J, Saavedra-Campos M, Baillie JK, Cleary P, Khaw FM, Lim WS, et al. The effectiveness of convalescent plasma and hyperimmune immunoglobulin for the treatment of severe acute respiratory infections of viral etiology: a systematic review and exploratory meta-analysis. J Infect Dis. 2015 Jan 1; 211(1):80-90.

38 U.S. Food and Drug Administration. Recommendations for Investigational COVID-19 Convalescent Plasma [Internet]. Maryland: Department of Health and Human Services; 2020

39 Chu CM, Cheng VC, Hung IF, Wong MM, Chan KH, Chan KS, et al. Role of lopinavir/ ritonavir in the treatment of SARS: initial virological and clinical findings. Thorax. 2004 Mar;59(3):252-6.

40 Sheahan TP, Sims AC, Graham RL, Menachery VD, Gralinski LE, Case JB, et al. Broadspectrum antiviral GS-5734 inhibits both epidemic and zoonotic coronaviruses. Sci Transl Med. 2017 Jun 28;9(396):eaal3653.

41 Sheahan TP, Sims AC, Leist SR, Schäfer A, Won J, Brown AJ, et al. Comparative therapeutic efficacy of remdesivir and combination lopinavir, ritonavir, and interferon beta against MERS-CoV. Nat Commun. 2020 Jan 10;11(1):222.

42 Grein J, Ohmagari N, Shin D, Diaz G, Asperges E, Castagna A, et al. Compassionate use of remdesivir for patients with severe Covid-19. N Engl J Med. 2020 Jun 11;382(24):2327-36.

43 Eastman RT, Roth JS, Brimacombe KR, Simeonov A, Shen M, Patnaik S, et al. Remdesivir: a review of its discovery and development leading to emergency use authorization for treatment of COVID-19. ACS Cent Sci. 2020; 6(5):672-83. 